\title{
Seasonal and Interannual Variations of Rainfall over Eastern Northeast Brazil
}

\author{
V. Brahmananda RaO, Marley C. De lima, and S. H. Franchito \\ Instituto Nacional de Pesquisas Espaciais, São Paulo, Brazil
}

(Manuscript received 14 November 1991, in final form 29 January 1993)

\begin{abstract}
Using the data for the period 1914-83, rainy and dry seasons of eastern Northeast (ENE) Brazil are determined. The principal rainy season is April through July ( $60 \%$ of the annual rainfall), and the principal dry season is September through December (10\% of the annual rainfall). The fall and winter rains over ENE Brazil are associated with southeasterly winds blowing perpendicular to the coast. The subtropical high in the South Atlantic modulates the strength and direction of winds along the coast that have a determining influence on the interannual variations of rainfall over ENE Brazil.

The possible link between the rainfall over ENE Brazil and SST anomalies in the Atlantic is examined. The SST anomalies of the season January, February, March, April (JFMA) in the southeast Atlantic are positively correlated with the rainfall anomalies of ENE Brazil. The sea surface temperature (SST) anomaly pattern frequently becomes established by January/February over southeast Atlantic suggesting the predictive value of SST anomalies over southeast Atlantic for the rainfall over ENE Brazil.
\end{abstract}

\section{Introduction}

Northeast (NE) Brazil is located in the tropics approximately between $1^{\circ} \mathrm{S}$ and $18^{\circ} \mathrm{S}$ and $35^{\circ} \mathrm{W}$ and $47^{\circ} \mathrm{W}$ and has an area of about a million square kilometers. This region is densely populated and is inhabited by more than 30 million people. It is characterized by large interannual rainfall variations and, in some years, severe droughts lead to intense human suffering and major economic problems.

Different rainfall regimes are identified in NE Brazil. In the north the principal rainy season is March and April; in the south, rains occur during the period December through February; and in the east the rainy season is May through July (Strang 1972). Spatial variation of annual rainfall is also high in this region. While portions of the interior dry region receive less than $600 \mathrm{~mm}$ of rainfall annually, the east coast receives around $2000 \mathrm{~mm}$ (Kousky and Chu 1978). Several studies have been made in attempts to understand the mechanisms of interannual variation of rainfall over NE Brazil (Hastenrath and Heller 1977; Moura and Shukla 1981; Rao et al. 1984; Rao and Marques 1984; Rao et al. 1986; and many others). Most of these studies, however, concentrate on the interior dry region while the rainfall characteristics of the eastern and southern parts remain almost unexplored. The purpose of the present study is to fill this lacuna by examining the rainfall characteristics of eastern Northeast (ENE) Brazil.

Corresponding author address: Dr. V. Brahmananda Rao, INPE-CP 515, Sao Jose dos Campos, São Paulo, Brazil, 12201.
We first identify the principal rainy and dry seasons of this region and then we study the interannual variation of rainfall. The possible roles of the Southern Oscillation (SO), the subtropical high in the South Atlantic, and the sea surface temperature (SST) in the Atlantic are examined.

Although numerical techniques have been used to predict monthly and seasonal means of atmospheric variables in the tropics (Shukla 1981), considerable research is still required before the feasibility of these methods is demonstrated. Until then, we must depend upon statistical and empirical methods for long-range forecasting of monthly and seasonal variables (Hastenrath 1986,1990$)$. Thus, it is highly desirable to document significant empirical relationships among various components of the ocean-atmosphere system. Such studies are essential for identifying the proper parameters to be used in the statistical and empirical techniques. The present study is one such attempt.

\section{Data sources}

Monthly rainfall data for 63 stations for the period 1914-83 were obtained from the Departamento $\mathrm{Na}$ cional de Obras Contra Secas (DNOCS) Brazil. The location of these raingage stations is shown in Fig. 1. Data are checked for errors. Means and standard deviations are calculated for each station and the individual values higher or lower than three standard deviations are eliminated. Not many values needed to be eliminated. Missing data were linearly interpolated.

To examine the possible link between the interannual variation of rainfall over ENE Brazil and the SO, 


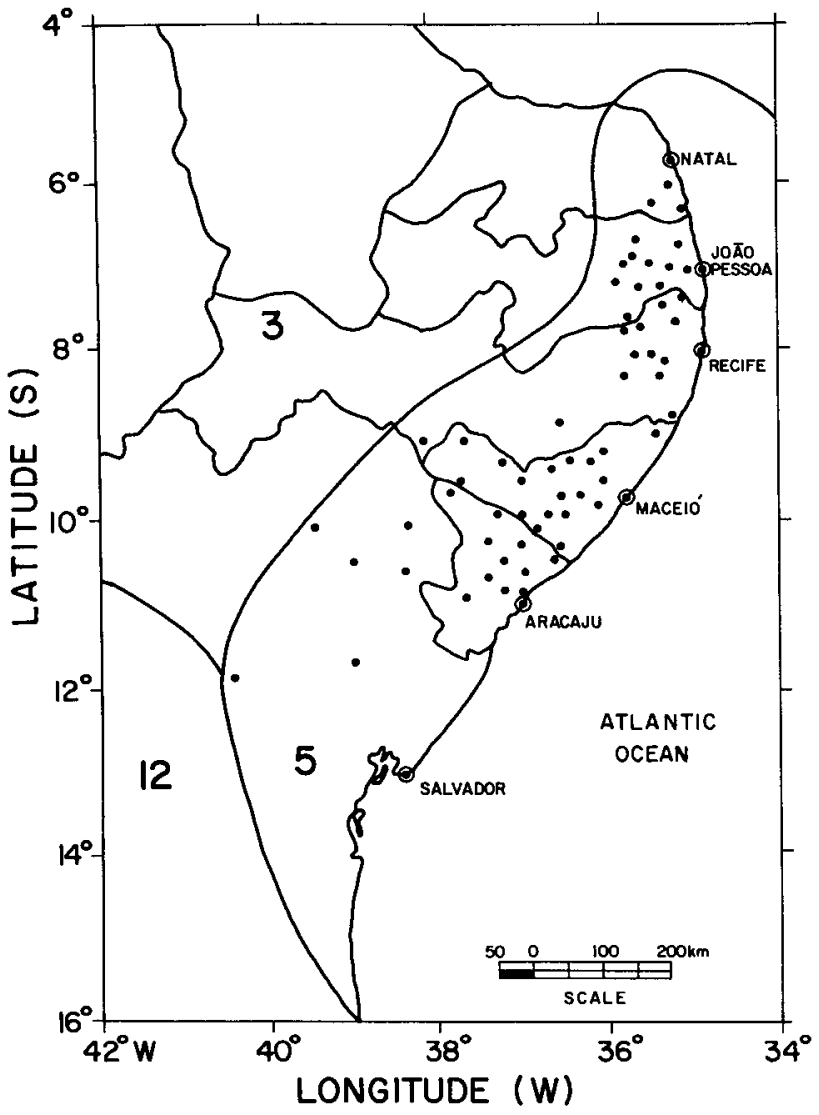

FIG. 1. Location of the raingage stations; 3,5 , and 12 represent, respectively, the principal months of rainfall (March, May, and December) for the three regions: NNE Brazil, ENE Brazil, and SNE Brazil.

we used the SO index data given by Parker (1983), which is simply Tahiti $\left(18^{\circ} \mathrm{S}, 150^{\circ} \mathrm{W}\right)$ minus Darwin $\left(12^{\circ} \mathrm{S}, 131^{\circ} \mathrm{E}\right)$ mean sea level pressure.

The subtropical high in the South Atlantic may play some role in the interannual variation of rainfall over ENE Brazil. Data that indicate the variation of the intensity and location of the subtropical high in the South Atlantic are difficult to obtain. We could get only the surface wind data for two stations, Abrolhos $\left(17^{\circ} 58^{\prime} \mathrm{S}\right.$, $\left.38^{\circ} 42^{\prime} \mathrm{W}\right)$ and Trindade Island $\left(20^{\circ} 30^{\prime} \mathrm{S}, 29^{\circ} 19^{\prime} \mathrm{W}\right)$. These data are obtained from Diretoria de Hidrografia e Navegação (DHN) of Brazil for the period 1964 through 1983. The data used were for 1200 UTC. From the original data of vector wind, $u$ and $v$ components are calculated. Seasonal cycle has been removed by calculating the deviation from the 20 -year individual monthly means.

Another important parameter that might influence the interannual variation of rainfall over ENE Brazil is the Atlantic SST. The SST data used in this study are taken from COADS (Comprehensive Ocean-Atmosphere Data Set) for the period 1940 through 1979. The COADS data contain most of the archived his- torical surface marine data. These data were summarized in a $2^{\circ} \times 2^{\circ}$ space grid after carefully checking for errors and duplication. Data availability is generally poor in the central South Atlantic and, due to the second World War, the period 1940-1945. Further details regarding the data can be found in Oort et al. (1987) and Nicholson and Nyenzi (1990).

\section{Annual and seasonal rainfall}

Figure 2 gives the mean (normal) annual rainfall for ENE Brazil. It can be seen that the region very near the coast receives $1600 \mathrm{~mm}$ annually and the amounts decrease rapidly toward the interior, reaching a meager $600 \mathrm{~mm}$. In general the isohyets are parallel to the coast except in a small region around $9^{\circ} \mathrm{S}$ and $37.5^{\circ} \mathrm{W}$ where there is a maximum of $1200 \mathrm{~mm}$. This secondary maximum is associated with the local orography (Borborema Plateau).

In order to define the dry and rainy seasons for ENE Brazil, we calculated the percentage contribution of all consecutive four-month combinations of monthly

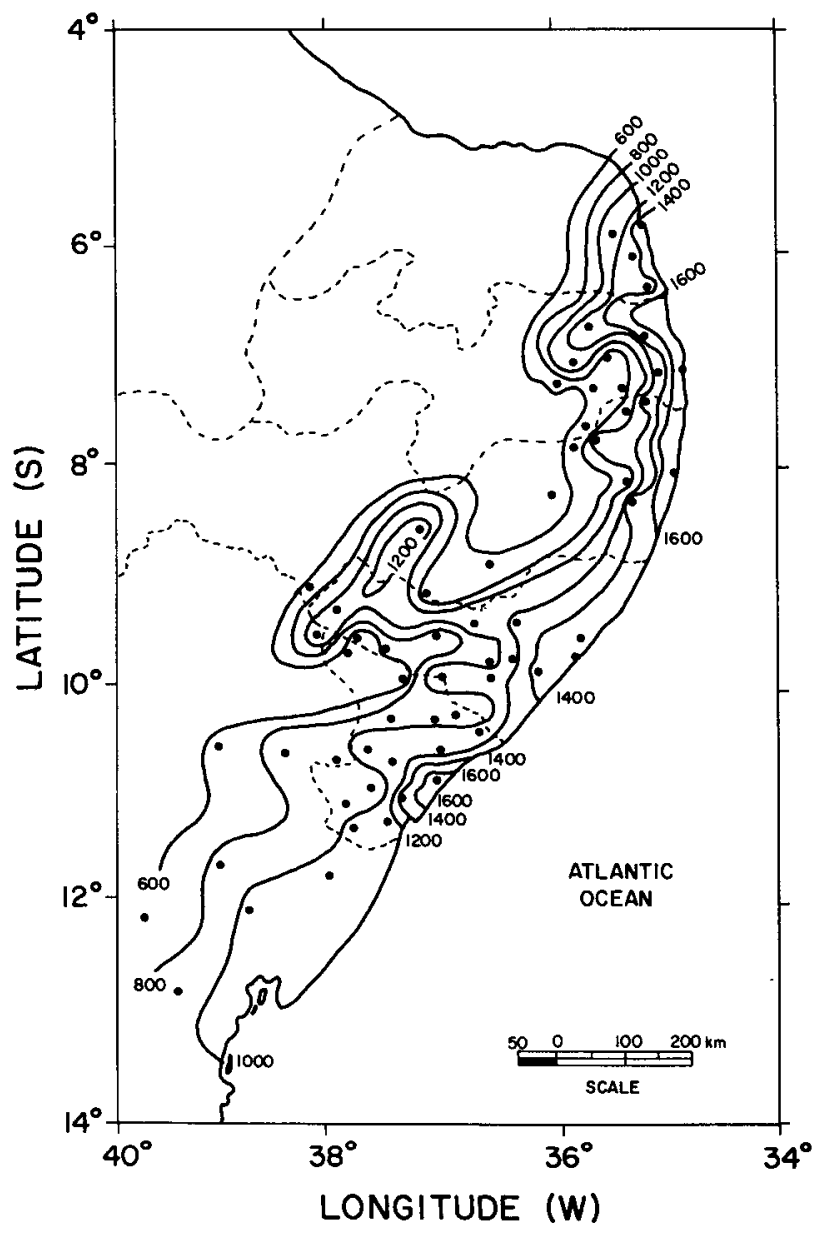

FIG. 2. Distribution of annual rainfall in millimeters over ENE Brazil. 


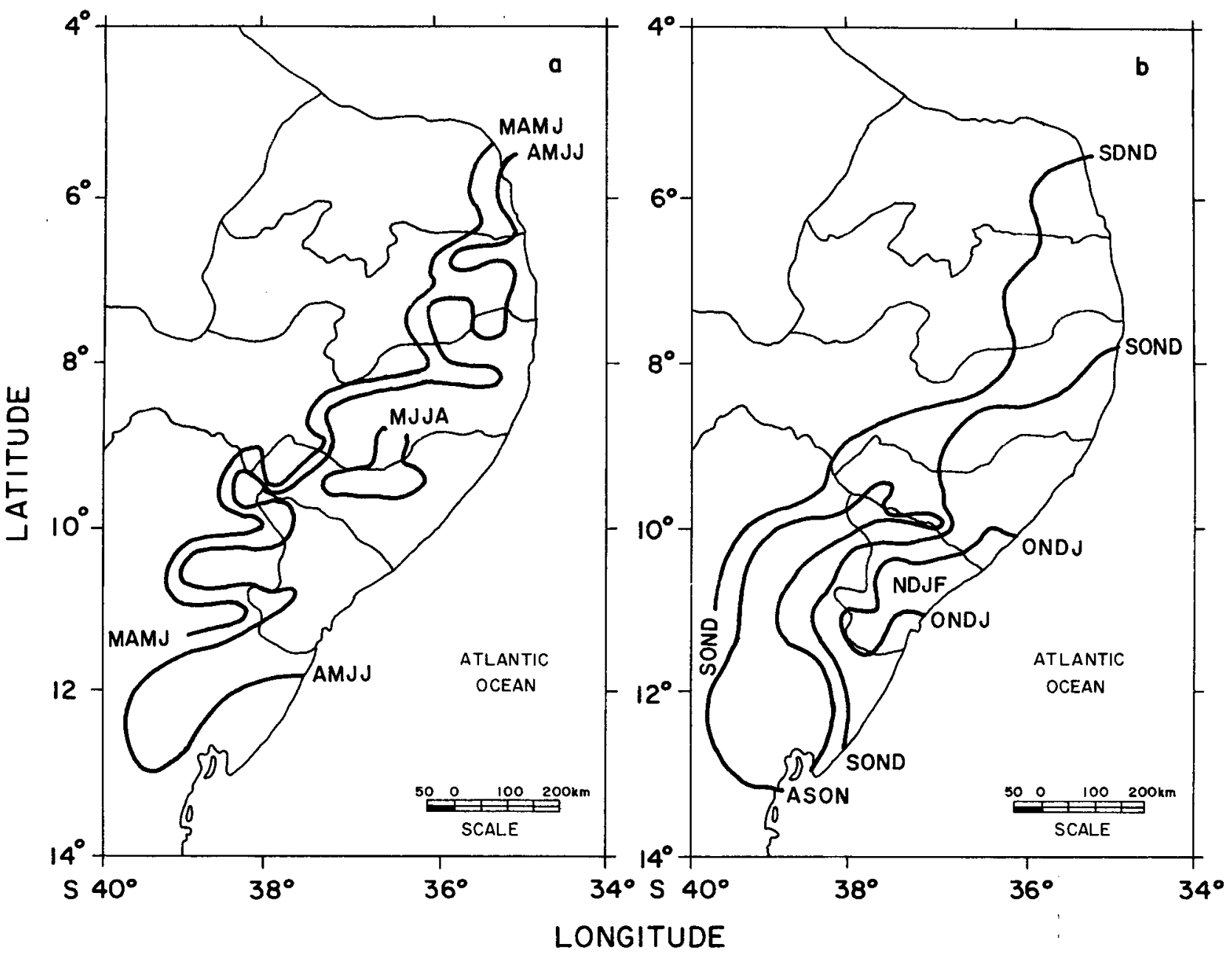

FIG. 3. (a) Rainy and (b) dry seasons. The four-letter symbols are taken from the first letters of the four consecutive months having highest or lowest rainfall.

rainfall to the annual rainfall. The period that contributes maximum percentage to the annual rainfall is the rainy season and the period that contributes minimum percentage is defined as the dry season. Figure 3 shows the rainy and dry seasons for ENE Brazil. The fourletter symbols are taken from the first letters of four consecutive months having the highest (rainy) or lowest (dry) percentage of annual rainfall than any other fourmonth period. It can be seen in Fig. 3a that the principal rainy season for ENE Brazil is April through July and explains $60 \%$ of the annual rainfall. The dry season for a major part of the region is September through December and explains only $10 \%$ of the annual rainfall.

Different explanations have been offered for the fall and winter maximum of rainfall over ENE Brazil. Yamazaki and Rao (1977) suggested the importance of westward-propagating cloud systems, which they detected in satellite imagery over the Atlantic Ocean. In a recent study, Chan (1990) confirmed the occurrence of these westward-propagating wave disturbances in winds over the Atlantic Ocean during the fall and winter seasons. Kousky (1979) has shown that heavy rainfall events in ENE Brazil are associated with southern cold fronts (or remnant shear lines). Kousky (1980) noted that the rainfall over ENE Brazil occurs mostly during the nighttime. He attributed this nocturnal maximum to the formation of a convergence zone between the land breeze and the mean flow. He also noted that the land breeze would be strongest during the fall and winter when the land-sea temperature contrast is highest.

Another factor one must consider in this context is the seasonal variation of coastal winds, which are connected to the seasonal variation of the intensity and position of the subtropical high in the South Atlantic Ocean. A careful examination of the monthly variation of sea level pressure and surface winds given by Hastenrath and Lamb (1977) shows that the subtropical high in the South Atlantic starts intensifying as the cold season advances, reaching its maximum in July. 
The coastal winds are easterly in the beginning of the year and by about April they start blowing perpendicular to the coast. Figure 4 shows the mean (1964-89) surface wind stress vectors over the Atlantic Ocean for the months of January, April, July, and October taken from Servain and Lukas (1990). The direction of the surface wind is the same as the direction of this vector and the surface wind speed is proportional to the magnitude of this vector. It can be seen in Fig. 4 that through April the direction of the wind is easterly or northeasterly along the coast. But during the period April through July, which coincides with the rainy season, the coastal winds are southeasterly. After that the coastal winds again become easterly or northeasterly as can be seen in the vectors for October. Thus, the fall and winter rains over ENE Brazil are associated with southeasterly winds blowing perpendicular to the coast. These southeasterly winds seem to favor the occurrence of a nocturnal convergence zone associated with the land breeze.

\section{Interannual variation of rainfall}

The interannual variability of rainfall over ENE Brazil is investigated by developing normalized rainfall
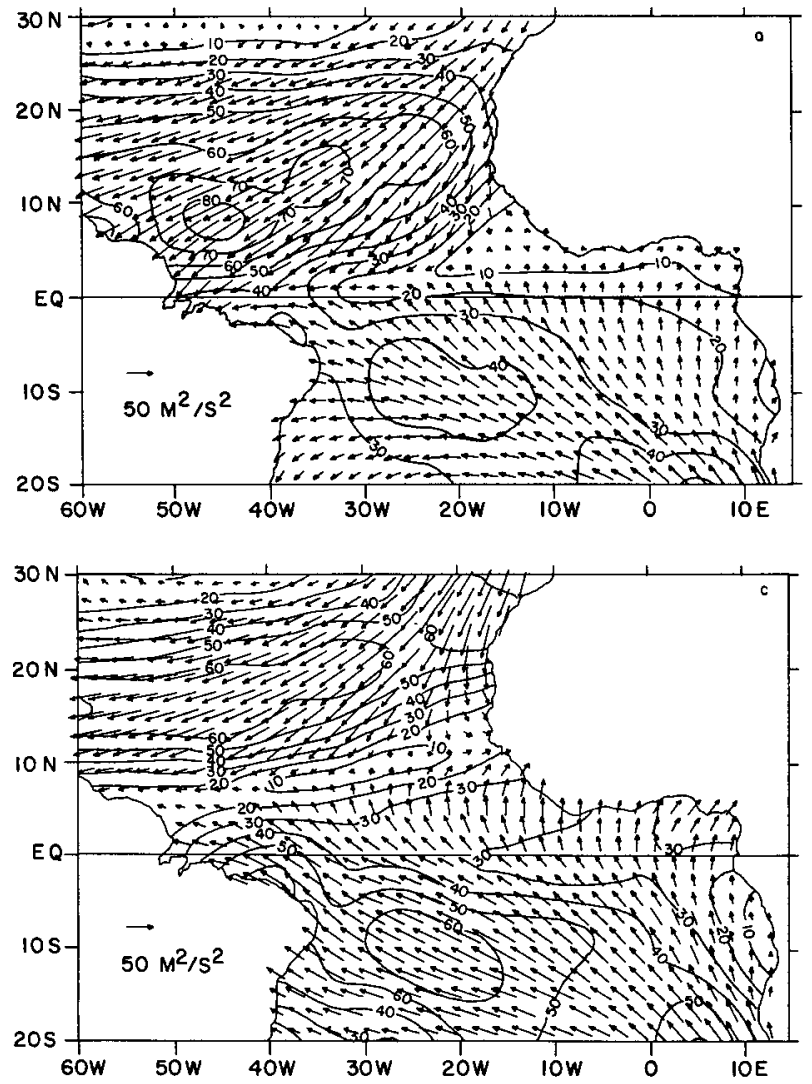

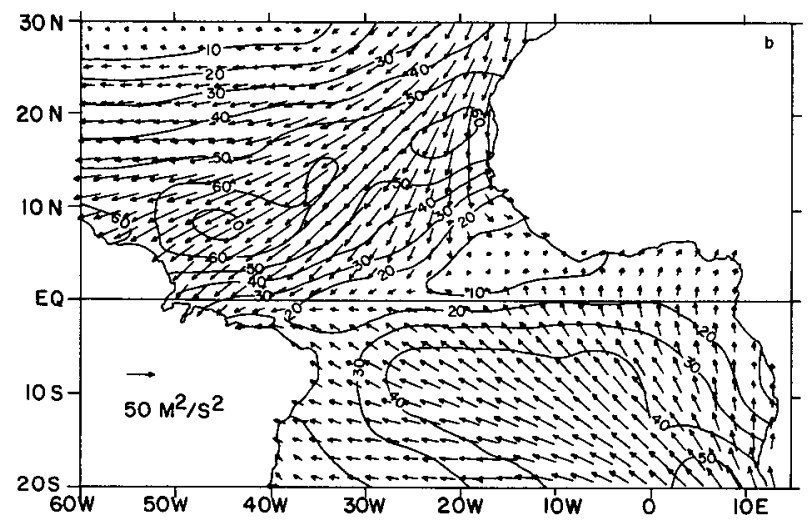

series. Normalized rainfall departure time series are obtained by expressing the departure of individual years from the mean in terms of the standard deviation. Averages for all stations of normalized departures form the normalized rainfall series (NRS) for ENE Brazil. Figure 5 shows the NRS for the annual and seasonal rainfall for the period 1914-83. It can be seen in Fig. 5 a that the positive deviations are, in general, greater in magnitude than the negative deviations. A similar tendency is also seen in Fig. 5b but to a lesser extent. The drought of 1983, however, seems to have been very intense.

Figure 6 shows the spatial distribution of composite deviations for ten drought $(1915,38,39,43,46,52$, $55,76,80$, and 81$)$ and ten flood $(1914,22,24,35$, $51,64,66,69,74$, and 77 ) years for the rainy season April, May, June, July (AMJJ). These years were selected as being the ten driest/wettest years on record. The year 1983 was not included in the drought years to avoid biasing the pattern with one exceptional year. It can be seen in Fig. 6 that the gradient of percentage deviation from the norm in the southern portion is in the north-south direction, whereas the gradient in the northern portion is in the east-west direction. Figure 6 shows the coherence of the drought and wet years

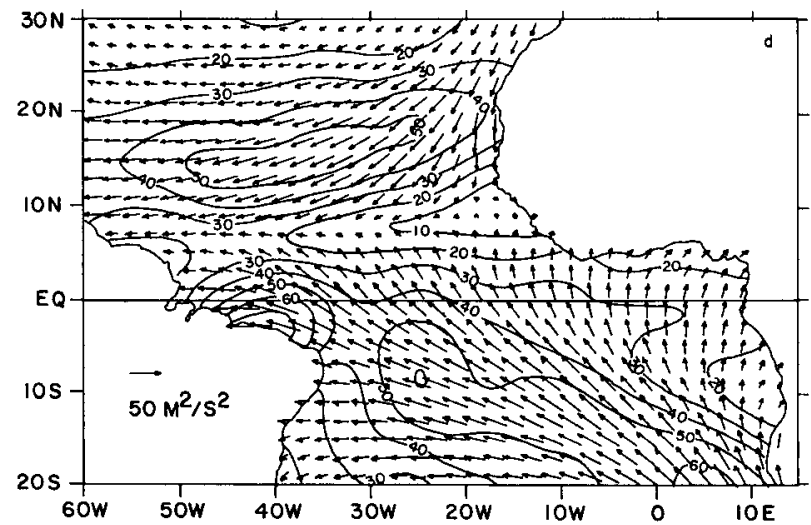

FIG. 4. Mean (1964-89) surface wind stress vector: (a) January, (b) April, (c) July, and (d) October. Taken from the atlas prepared by Servain and Lukas (1990). 

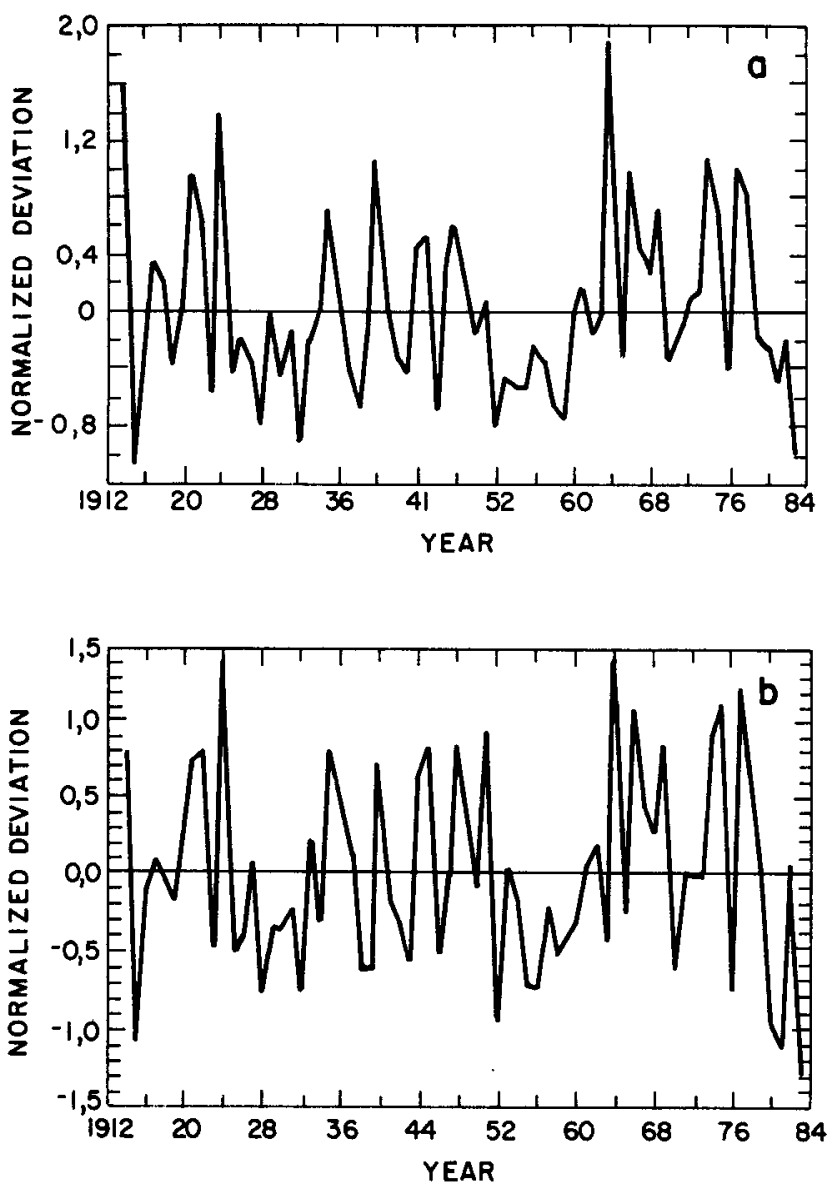

FiG. 5. Normalized rainfall series for the (a) annual and (b) seasonal (AMJJ) cases.

(according to the rainfall index) in the entire region. For example, Fig. 6a shows that drought years are less coherent than the wet ones and that the largest coherence for wet and dry years is found in the interior.

To establish the connection between the rainfall over northern Northeast (NNE) Brazil and ENE Brazil, we calculated the correlation coefficient (CC) between the NRS (annual) for ENE Brazil and the rainfall series for NNE given by Hastenrath (1985) for the period 1914-83. The CC is 0.36 . This suggests that some of the processes that affect NNE Brazil also affect ENE Brazil. We know that severe droughts, such as that of 1983, occur over the entire NE Brazil area, including the eastern part. However, the small correlation together with the fact that rainy seasons are different in the two regions shows that the two regimes are different and warrant separate studies.

\section{a. Connection with the Southern Oscillation}

Table 1 shows the CC between the SO index and seasonal NRS for ENE Brazil for the period 1948-83. All possible combinations of consecutive four-month periods are taken. It can be seen that, in general, the $\mathrm{CCs}$ are small. The $\mathrm{CC}$ for the rainy season AMJJ is small and negative. The CC for the dry season August, September, October, November (ASON) is somewhat higher and positive. This indicates that during the $\mathrm{El}$ Niño years the low rainfall over ENE Brazil during the dry season will be further reduced. This low correlation between SOI and rainfall agrees with the earlier results of Ropelewski and Halpert (1987), Rogers (1988), and Aceituno (1988).

\section{b. Connection with the subtropical high in the South Atlantic}

In the South Atlantic the surface circulation is dominated throughout the year by the subtropical high. On the western side of this system near the east coast of NE Brazil the flow is diffluent. The line of bifurcation of this diffluent flow varies in position, such that during the fall and winter the flow is perpendicular to the coast of ENE Brazil. As mentioned earlier, this type of flow favors the fall and winter precipitation. Thus, interannual variation of rainfall over ENE Brazil is probably associated with the interannual variation in the strength and position of the subtropical high. Table 2 gives the mean surface zonal $(u)$ and meridional $(v)$ wind components for the period 1964-83 at Trindade Island and Abrolhos. It can be seen that the general direction of the wind is northeasterly, as can be expected since both the stations are located on the western part of the South Atlantic high. However during the winter season (MJJA), the rainy season of ENE Brazil, the winds are stronger and are southeasterly. Although the position and intensity of the subtropical high are important for the winds in the South Atlantic Ocean, the intertropical convergence zone (ITCZ) might also play some role in determining the winds at the two stations considered.

Next CCs are calculated between the wind components (four-month seasonal averages) at Trindade Island and Abrolhos and the seasonal NRS for ENE Brazil for the period 1964-83. The correlation with the zonal wind component (not shown) is generally small. Table 3 shows the simultaneous $\mathrm{CC}$ for the meridional wind components at the two stations. At both stations the CCs for the rainy season (AMJJ) are high and significant at the $99 \%$ level. Thus, the southerlies at both stations are associated with higher rainfall and the CCs are higher for Abrolhos. Figure 7a shows the meridional wind anomalies for Abrolhos and rainfall anomalies over ENE Brazil for the rainy season AMJJ. The CC between the two series is 0.63 (significant at $99 \%$ level).

The existence of a long-term trend introduces persistence in the rainfall series. Persistence reduces the degrees of freedom (Quenouille 1952) and makes the correlation statistically less significant. In order to determine whether there is persistence in the rainfall series for the 20-year period, 1964-1983, we calculated the serial correlation up to a lag of five years. Table 5 shows 


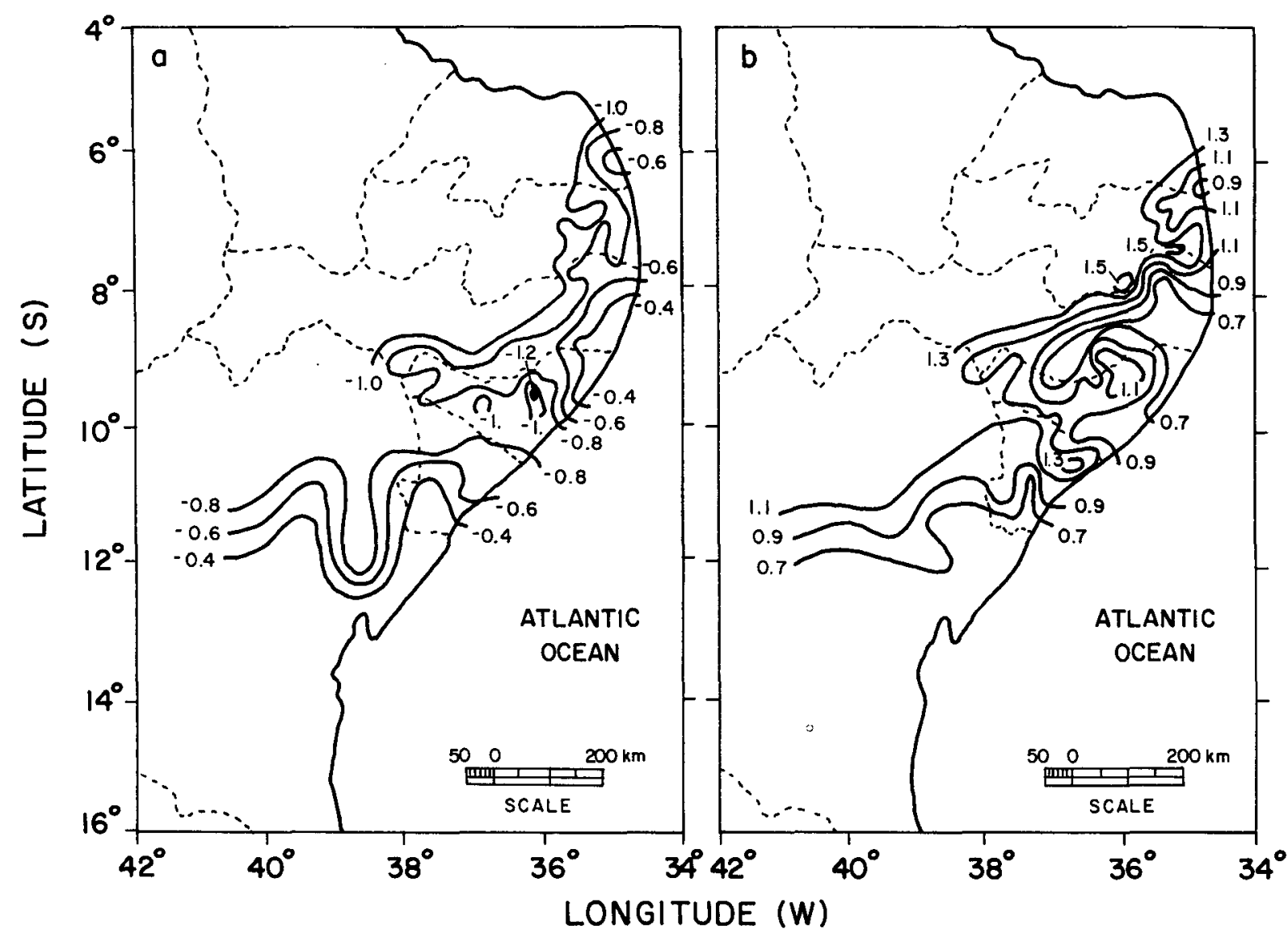

FIG. 6. Spatial distribution of the composite deviation from normal in percentage (divided by 100) for (a) ten drought years $(1915,38,39,43,46,52,55,76,80$, and 81$)$ and $(b)$ ten flood years $(1914,22,24,35,51,61,66,69,74$, and 77$)$.

that the serial correlation is generally small except for a few higher CCs, suggesting lack of persistence. To confirm the lack of trend, the 20-year rainfall series are subjected to the test of Mann (coefficient $t$ of Kendall) (Sneyers 1975). This showed the lack of trend in the 20-year rainfall data. However, the rainfall series and wind data considered are only of small duration ( 20 years) and in the future the relationship between the meridional wind in the South Atlantic and ENE

TABLE 1. Correlation coefficient between the Southern Oscillation index (SOI) and normalized rainfall series (NRS) for ENE Brazil.

\begin{tabular}{cc}
\hline SOI $\times$ NRS & CC \\
\hline JFMA $\times$ JFMA & 0.06 \\
FMAM $\times$ FMAM & 0.22 \\
MAMJ $\times$ MAMJ & 0.07 \\
AMJJ $\times$ AMJJ & -0.03 \\
MJJA × MJJA & -0.06 \\
JJAS × JJAS & 0.11 \\
JASO × JASO & 0.33 \\
ASON × ASON & 0.30 \\
SOND × SOND & 0.03 \\
Annual $\times$ Annual & 0.11 \\
\hline
\end{tabular}

Brazil rainfall should be confirmed with larger series of data.

Lagged CCs are also calculated between the surface winds at the two stations and the seasonal NRS. All possible combinations of four-month periods are taken. Only CCs that are significant at $95 \%$ level or higher are given in Table 4 . The CCs with zonal winds are small and are not included in Table 4. Again the CCs are substantially higher for Abrolhos. Meridional wind

TABLE 2. Seasonal mean winds $\left(\mathrm{m} \mathrm{s}^{-1}\right)$ for 20 years (1964-83) at Trindade Island and Abrolhos: $u$ is zonal wind and $v$ is meridional wind. Positive sign for $u$ indicates westerly wind and negative sign indicates easterly wind. Positive sign for $v$ indicates southerly wind and negative sign indicates northerly wind.

\begin{tabular}{llrlrr}
\hline \hline & \multicolumn{2}{c}{ Trindade Island } & & \multicolumn{2}{c}{ Abrolhos } \\
\cline { 2 - 3 } \cline { 5 - 6 } & $u$ & $v$ & & $u$ & $v$ \\
\hline JFMA & -4.7 & -0.8 & & -4.3 & -1.6 \\
MJJA & -5.5 & 1.9 & & -6.1 & 2.1 \\
SOND & -4.1 & -1.4 & & -5.9 & -3.7 \\
Annual & -4.8 & -0.1 & & -5.4 & -1.1 \\
\hline
\end{tabular}


TABLE 3. Simultaneous CC between the meridional component of surface wind and the normalized rainfall series (NRS). The CCs significant at the $95 \%$ level (by two-sided Student's $t$-test) are marked with one star and those with two stars are significant at the $99 \%$ level. The CCs that are less than $95 \%$ significant are not included.

\begin{tabular}{ccc}
\hline \hline & $\begin{array}{c}\text { Trindade } \\
\text { Island }\end{array}$ & Abrolhos \\
\hline FMAM $\times$ FMAM & $0.41^{*}$ & $0.45^{*}$ \\
MAMJ $\times$ MAMJ & $0.47^{*}$ & $0.62^{* *}$ \\
AMJJ $\times$ AMJJ & $0.49^{* *}$ & $0.63^{* *}$ \\
MJJA $\times$ MJJA & $0.43^{*}$ & $0.47^{*}$ \\
JJAS $\times$ JJAS & $0.47^{*}$ & $0.47^{*}$ \\
ASON $\times$ ASON & - & $0.39^{*}$ \\
\hline
\end{tabular}
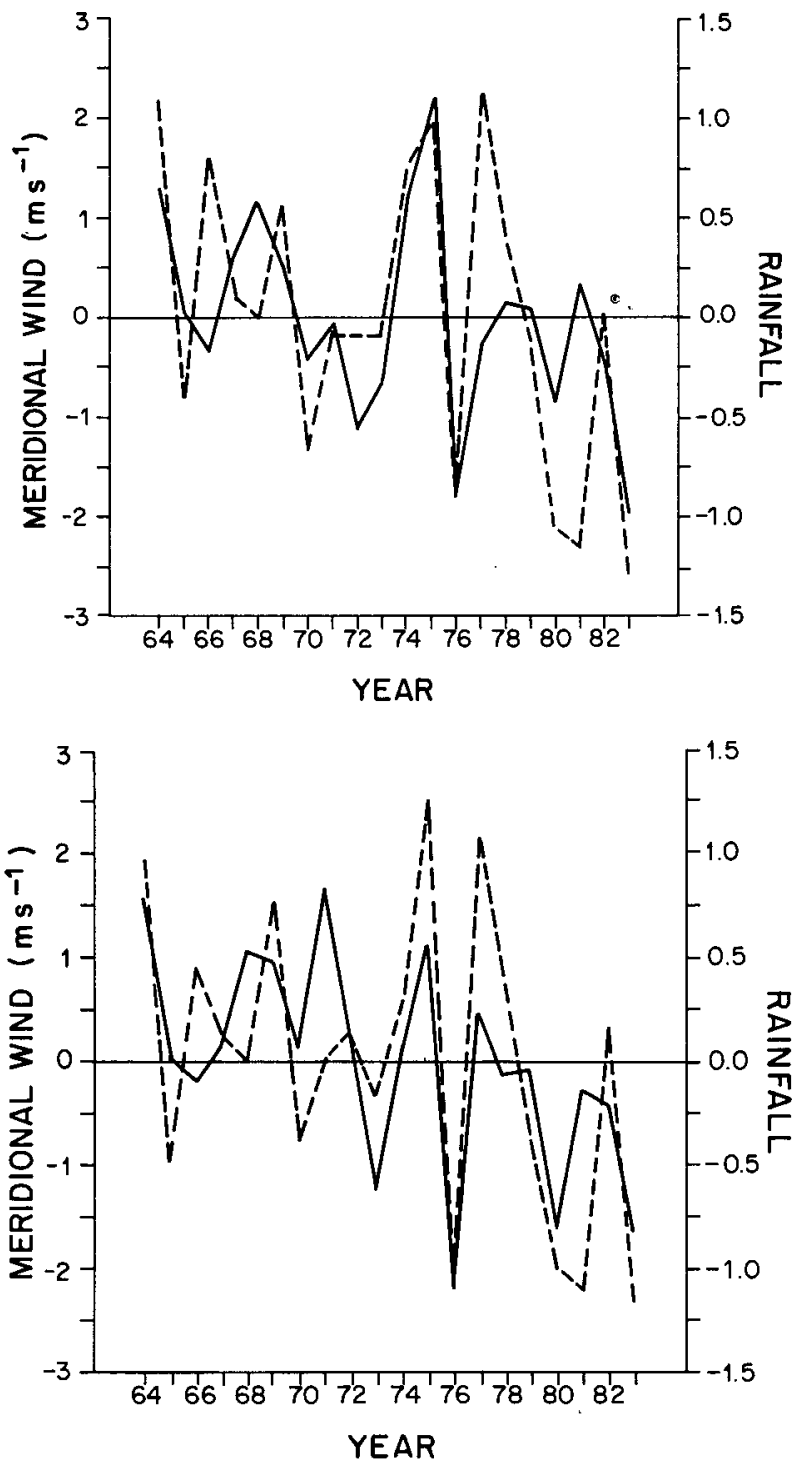

FIG. 7. (a) Time series of AMJJ meridional wind (continuous line) over Abrolhos and rainfall (broken lines) over ENE Brazil; (b) time series of JFMA meridional wind (continuous line) over Abrolhos and rainfall (broken lines) of MJJA over ENE Brazil.
TABLE 4. Lagged correlation coefficient between the meridional wind component of surface wind and the NRS.

\begin{tabular}{lll}
\hline \hline & $\begin{array}{c}\text { Trindade } \\
\text { Island }\end{array}$ & Abrolhos \\
\hline JFMA $\times$ MJJA & - & $0.72^{* *}$ \\
FMAM $\times$ JJAS & $0.37^{*}$ & $0.70^{* *}$ \\
MAMJ $\times$ JASO & $0.42^{*}$ & $0.55^{* *}$ \\
\hline
\end{tabular}

at Abrolhos for JFMA season is highly significantly correlated with the precipitation of MJJA. This indicates the predictive value of the surface winds at Abrolhos. Figure $7 \mathrm{~b}$ shows the meridional wind anomalies for the season JFMA and the rainfall anomalies over ENE Brazil for the rainy season MJJA. The CC between the series is 0.72 ( significant at $99 \%$ level).

The foregoing discussion suggests that the rainfall over ENE Brazil is modulated by the meridional wind over the western Atlantic Ocean. The explanation relating these two parameters should await further analysis, including theoretical and numerical studies. However, some conjectures can be made. Anomalous southerly flow over the western Atlantic, associated with higher rainfall over ENE Brazil, might favor penetration of southern cold fronts. In an earlier study, Kousky (1979) suggested that episodes of higher rainfall over ENE Brazil are associated with the penetration of cold fronts (or remnant shear lines). It would be interesting to verify whether the years of higher rainfall over ENE Brazil (stronger southerly winds over the western Atlantic) are indeed associated with a higher number of cold fronts penetrating ENE Brazil. In any case, a study relating the anomalous southerly flow, southern cold fronts, and the Atlantic subtropical high would be of interest.

\section{c. Connection with Atlantic sea surface temperature}

To identify regions of the Atlantic, if any, that correlate with the rainfall over ENE Brazil, we correlated the AMJJ NRS mentioned in the previous section with the SST anomalies for the period 1940-79. This methodology is similar to that used previously by Markham and McLain (1977) and Moura and Shukla (1981) for NNE Brazil. The SST anomalies are calculated by subtracting the climatological mean for each month from individual monthly values. This effectively removes the seasonal cycle. Several combinations of 2-, 3-, and 4month periods of SST anomalies were correlated with NRS in order to find out the period for which the CCs are highest. Figure 8 a shows the isolines of $\mathrm{CC}$ between SST anomalies of JFMA and NRS. It can be seen that there is a large region of positive correlation in the South Atlantic with a CC of 0.49 ( significant at $99.5 \%$ level). There are two small regions of low negative correlation to the north and south of this region. Not evident in Fig. 8a is the dipole structure, found in studies 


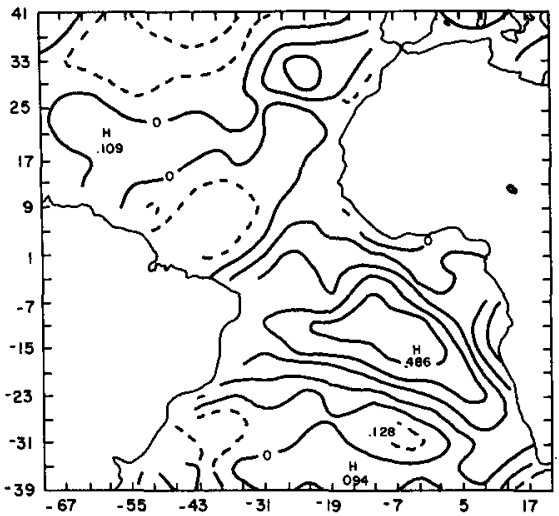

(a)

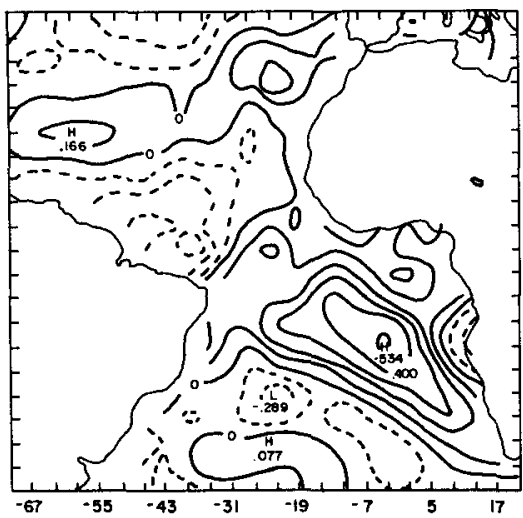

(b)

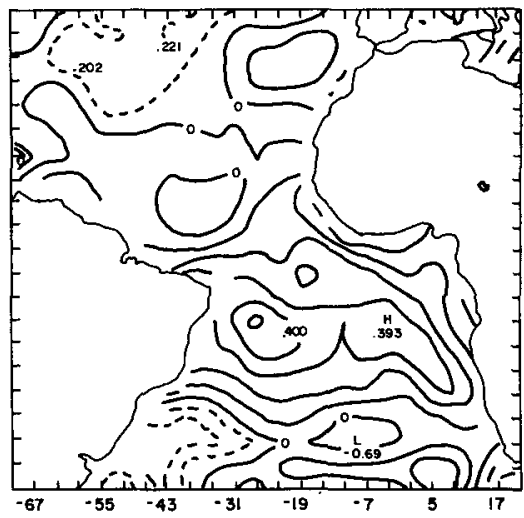

(c)

FIG. 8. Isolines of CC between SST anomalies and normalized rainfall series of AMJJ for 40 years (1940-79): (a) with SST anomalies of JFMA, (b) with SST anomalies of JF, and (c) with SST anomalies of MA. Broken lines indicate negative correlation coefficients.

of correlation between rainfall over NNE Brazil and Atlantic SST (Hastenrath and Heller 1977; Moura and Shukla 1981). After completing the present paper, we happened to see a recent paper by Houghton and Towrre (1992). Results shown in that paper agree with results shown here. Figure $8 \mathrm{~b}$ shows the isolines of $\mathrm{CC}$ between SST anomalies of JF and NRS for AMJJ. The configuration of regions of positive and negative correlation is essentially the same as in Fig. 8a. The positive $\mathrm{CC}$ in the South Atlantic is higher compared to that seen in Fig. 8a. The SST anomalies in the South Atlantic, associated with AMJJ rainfall anomalies, are already established by the beginning of the year, showing the potential predictive value of SST anomalies in the South Atlantic for rainfall anomalies over ENE Brazil. Figure 8c shows the isolines of $\mathrm{CC}$ for the twomonth period March/April (MA) with NRS. It can be seen that the region of high correlation moves near the coast. In Fig. 8 it is interesting to see that areas of the highest correlation are oriented along the ship route on the eastern Atlantic. This gives more confidence to the present results.

TABLE 5. Serial correlation coefficients for rainfall over ENE Brazil for different seasons. Numbers 1 to 5 represent the lags in years.

\begin{tabular}{lrrrrr}
\hline \hline & \multicolumn{5}{c}{ Lag } \\
\cline { 2 - 6 } & \multicolumn{1}{c}{1} & \multicolumn{1}{c}{ 2 } & \multicolumn{1}{c}{3} & \multicolumn{1}{c}{4} & \multicolumn{1}{c}{5} \\
\hline JFMA & -0.31 & 0.09 & -0.24 & 0.19 & -0.07 \\
FMAM & -0.37 & 0.04 & -0.03 & -0.04 & 0.08 \\
MAMJ & -0.11 & -0.06 & 0.25 & -0.13 & 0.15 \\
AMJJ & -0.03 & 0.21 & 0.20 & -0.19 & -0.01 \\
MJJA & -0.19 & 0.18 & 0.20 & -0.13 & 0.04 \\
JJAS & -0.21 & 0.24 & 0.13 & -0.03 & -0.04 \\
JASO & 0.07 & 0.31 & 0.07 & -0.02 & -0.23 \\
ASON & 0.12 & 0.20 & -0.14 & -0.14 & -0.38 \\
SOND & 0.31 & 0.16 & -0.08 & -0.18 & -0.15 \\
\hline
\end{tabular}

The SST anomalies sometimes contain a long-term trend (Wright and Wallace 1983; Barnett 1984; Rao and Goswami 1988) that introduces persistence in the SST series. As mentioned earlier, persistence reduces the degrees of freedom (Quenouille 1952) and makes the correlation statistically less significant. We have calculated the serial correlation of SST up to a lag of five years for three boxes. These are shown in Table 5 . The location of these boxes is shown in Fig. 9. These boxes are selected such that they represent regions of high CC (between SST and rainfall) for the corresponding periods. The SST anomalies are averaged over the grid points contained in each box. The number of years used to calculate the serial correlations is around 40. It can be seen in Table 6 that the serial correlation

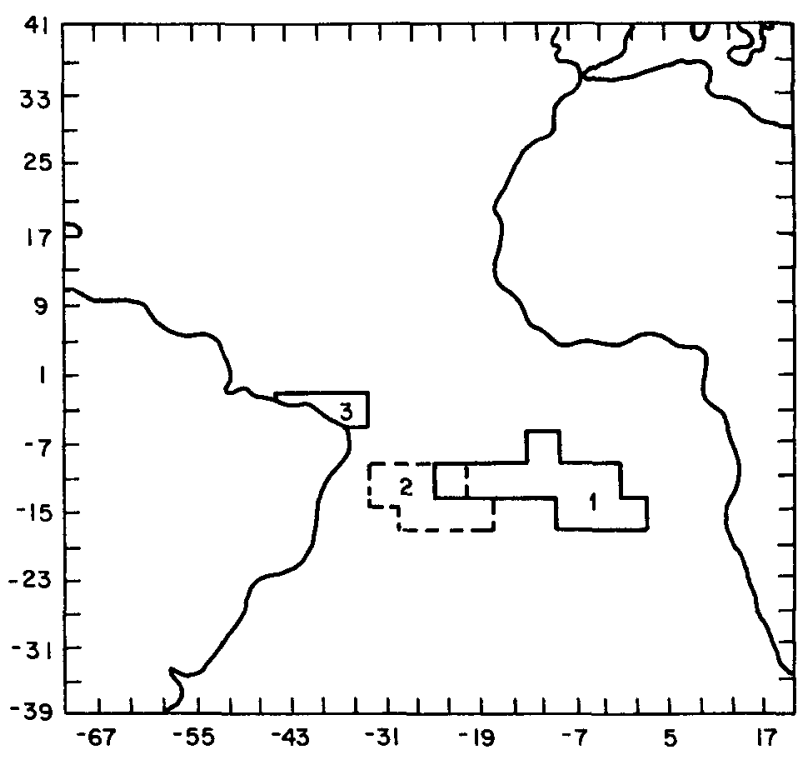

FIG. 9. Location of the boxes used to calculate serial correlation. 
is small, suggesting lack of persistence, at least in the 40-year period considered. Serial correlation is small in the rainfall index also. Thus, the CC of around 0.5 noted earlier between the seasonal (AMJJ) NRS for ENE Brazil and SST series (for JFMA or JF) for the 40-year period is highly significant.

The physical mechanism that relates the SST over the South Atlantic Ocean to the rainfall over ENE Brazil should await further studies. However, a preliminary explanation can be attempted. Higher SST over the South Atlantic favors higher evaporation. Larger transport of water vapor to ENE Brazil can occur with a larger number of southern fronts, which are suggested in section $4 \mathrm{~b}$ to be associated with anomalous southerly flow over western Atlantic during years of higher rainfall.

Figure 10 shows the scatter diagram between normalized rainfall over ENE Brazil and normalized JF SST anomalies over an area where the CC is highest in box 1 . It is seen that most of the heavy rainfall years are in the upper right-hand quadrant and most of the drought years are in the lower left-hand quadrant. Most of the points ( 30 ) fall in these two quadrants. Only ten points fall in the other two quadrants. In a sample of 40 years, there is only one year (1975) for which the normalized rainfall anomaly is greater than +1 but has a negative SST anomaly. Also no point falls in either the upper left quadrant (with normalized SST anomaly greater than +1 and normalized rainfall anomaly less than -1 ) or the lower right quadrant (with normalized SST anomaly less than -1 and normalized rainfall anomaly greater +1$)$. The $\mathrm{CC}$ between the two series is +0.53 . Since serial correlations for both the rainfall and the SST are small, the correlation is highly significant. Thus, JF SST over the southeast Atlantic seems to be a potentially useful predictor for the seasonal rainfall over ENE Brazil.

\section{Summary and concluding remarks}

In the present article we discuss the characteristics of rainfall over ENE Brazil. Using the data for the period 1914-83, we determined rainy and dry seasons. The principal rainy season is April through July and

TABLE 6. Serial correlation coefficients for SST in the three boxes and rainfall over ENE Brazil. Numbers 1 to 5 represent the lags in years.

\begin{tabular}{|c|c|c|c|c|}
\hline LAG & $\begin{array}{l}\text { ENE Brazil } \\
\text { rainfall }\end{array}$ & $\begin{array}{c}\text { SST } \\
\text { JFMA } \\
\text { Box } 1\end{array}$ & $\begin{array}{c}\text { SST } \\
\text { MA } \\
\text { Box } 2\end{array}$ & $\begin{array}{c}\text { SST } \\
\text { AMJJ } \\
\text { Box } 3 \\
\end{array}$ \\
\hline 1 & -0.13 & 0.23 & 0.31 & -0.03 \\
\hline 2 & 0.08 & -0.06 & 0.25 & 0.01 \\
\hline 3 & 0.25 & 0.03 & 0.00 & -0.00 \\
\hline 4 & -0.04 & 0.05 & -0.01 & 0.01 \\
\hline 5 & 0.01 & 0.22 & 0.04 & -0.22 \\
\hline
\end{tabular}

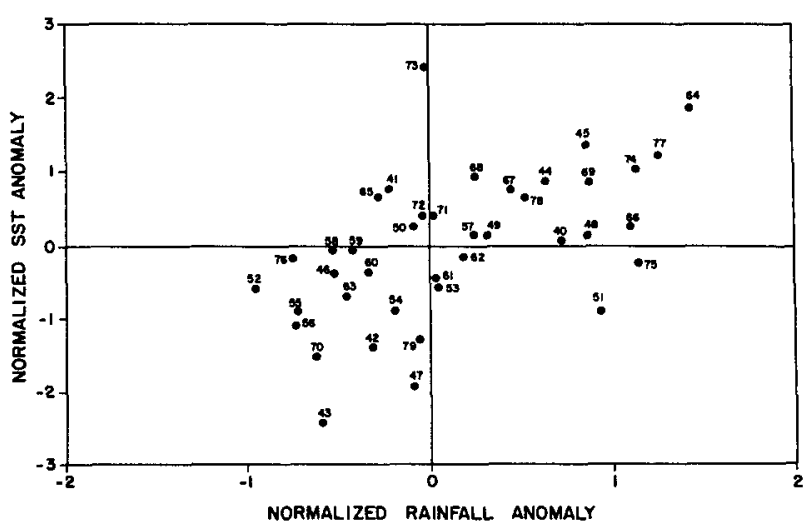

FIG. 10. The scatter diagram between normalized rainfall over ENE Brazil for AMJJ and normalized JF, SST anomalies in box 1 . The numbers denote years (minus 1990).

explains $60 \%$ of the annual rainfall. The dry season is September through December and explains only $10 \%$ of the annual rainfall. The possible processes that are responsible for the fall and winter rains in this region are mentioned. A careful examination of the seasonal change of winds along the coast suggests that the fall and winter rains are associated with southeasterly winds blowing perpendicular to the coastline.

Next, interannual variation of rainfall over ENE Brazil is discussed. It is found that the $\mathrm{CC}$ between the SO index and rainfall over ENE Brazil is small. However intense El Niño years such as 1983 are, in general, years of drought throughout NE Brazil including the eastern region. The intensity and location of the subtropical high in the South Atlantic seems to have an important effect on the ENE Brazil rainfall. The subtropical high in the South Atlantic modulates the strength and direction of winds along the coast that have a determining influence on rainfall. Southerlies at Abrolhos correlate strongly with the rainfall over ENE Brazil.

Sea surface temperature anomalies in the tropics are known to influence the rainfall (Shukla 1975; Moura and Shukla 1981). Using 40 years (1940-79) of SST data we examined the possible link between the rainfall over ENE Brazil and SST anomalies in the Atlantic. The SST anomalies of the season JFMA in the southeast Atlantic are strongly related to the rainfall anomalies of ENE Brazil. The SST anomalies seem to already become established by JF over the SE Atlantic. This suggests the predictive value of SST anomalies over the SE Atlantic for the rainfall over ENE Brazil.

The physical process through which the southeastern Atlantic influences the rainfall over ENE Brazil can be conjectured. Southern cold fronts penetrating ENE Brazil may be important in enhancing precipitation during the years of anomalous southerlies over the western Atlantic. Evaporation may be the factor that links anomalously higher SST over the South Atlantic 
to the higher rainfall over ENE Brazil. In any case further research is needed to clarify these issues.

Acknowledgments. Thanks are due to Dr. Clóvis A. Sansigolo for the COADS data, which he obtained from the Japanese Meteorological Agency. Thanks are also due to the official reviewers and the editor, Dr. Peter J. Lamb, for their useful comments on the manuscript.

\section{REFERENCES}

Aceituno, P., 1988: On the functioning of the Southern Oscillation in the South American sector. Part I: Surface Climate. Mon. Wea. Rev., 116, 505-524.

Barnett, T. P., 1984: Long-term trends in sea surface temperature. Mon. Wea. Rev., 112, 303-312.

Chan, S. C., 1990: Analysis of the easterly wave disturbances over South Atlantic Ocean. M.S. thesis. INPE-5222-TDL/437. [Available from Instituto Nacional de Pesquisas Espaciais, 12201, CP 515, Sâo José dos Campos, Sâo Paulo, Brazil.] 104 pp.

Hastenrath, S., 1985: Climate and Circulation in the Tropics, D. Reidel, 253-329.

- 1986: On climate prediction in the tropics. Bull. Amer. Meteor. Soc., 67, 692-702.

- 1990: Tropical climate prediction: A progress report, 198590. Bull. Amer. Meteor. Soc., 75, 819-825.

- and L. Heller, 1977: Dynamics of climatic hazards in Northeast Brazil. Quart. J. Roy. Meteor. Soc., 103, 77-92.

- - and P. J. Lamb, 1977: Climatic Atlas of the Tropical Atlantic and Eastern Pacific Oceans. Madison: The University of Wisconsin Press. 113 pp.

Houghton, R. W., and Y. M. Towrre, 1992: Characteristics of lowfrequency sea surface temperature flutuations in the tropical Atlantic. $J$. Climate, 5, 765-771.

Kousky, V. E., 1979: Frontal influences on northeast Brazil. Mon. Wea. Rev., 107, 1140-1153.

- 1980: Diurnal rainfall variation in Northeast Brazil. Mon. Wea. Rev., 108, 488-498.

- , and P. S. Chu, 1978: Flutuations in annual rainfall for Northeast Brazil. J. Meteor. Soc. Japan, 56, 457-465.

Markham, C. G., and D. R. McLaim, 1977: Sea surface temperature related to rain in Ceara, northeast Brazil. Nature, 265, 320-323.

Moura, A. D., and J. Shukla, 1981: On the dynamics of drought in Northeast Brazil. J. Atmos. Sci., 33, 2553-2675.
Nicholson, S. E., and B. S. Nyenzi, 1990: Temporal and spatial variability of SSTs in the Tropical Atlantic and Indian Ocean. $M e-$ teor. Atmos. Phys., 42, 1-17.

Oort, A. H., R. W. Reynolds, and C. F. Ropelewski, 1987: Historical trends in the surface temperature over the oceans based on the COADS. Climate Dyn., 2, 29-38.

Parker, D. E., 1983: Documentation of a southern oscillation index. Metor. Mag., 112, 184-188.

Quenouille, M. H., 1952: Associated Measurements. Butterworths Scientific.

Rao, K. G., and B. N. Goswami, 1988: Interannual variations of sea surface temperature over the Arabian Sea and the Indian Monsoon: A new perspective. Mon. Wea. Rev., 116, 558-568.

Rao, V. B., and V. S. Marques, 1984: Water vapor characteristics over Northeast Brazil during two contrasting years. J. Climate and Appl. Meteor., 23, 440-444.

,-- and J. P. Bonatti, 1984: On the possibility of barotropic instability over Northeast Brazil. Tellus, 36A, 207-210.

-, P. Satyamurty, and J. I. B. de Brito, 1986: On the 1983 drought in Northeast Brazil. J. Climatol., 6, 43-51.

Rogers, J. C., 1988: Precipitation variability over the Caribbean and Tropical Americas associated with the southern oscillation. $J$. Climate, 1, 172-182.

Ropelewski, C. F., and M. S. Halpert, 1987: Global and regional scale precipitation patterns associated with the El Niño/Southern Oscillation. Mon. Wea. Rev., 115, 1606-1626.

Servain, J., and S. Lukas, 1990: Climatic Atlas of the Tropical Atlantic Wind Stress and Sea Surface Temperature 1985-1989. Instituit Français de Recherche pour l'Exploitation de la Mer, 143 pp.

Shukla, J., 1975: Effect of Arabian sea-surface temperature anomaly on Indian summer monsoon: a numerical experiment with GFDL model. J. Atmos. Sci., 32, 503-511.

- 1981: Dynamic predictability of monthly means. J. Atmos. Sci., 38, 2547-2572.

Sneyers, R., 1975: Sur l'analyse statistique des séries d'observations. World Meteorological Organization (WMO). Technical Note No. 143, $192 \mathrm{pp}$.

Strang, D. M. G. D., 1972: Climatological analysis of rainfall normals in Northeast Brazil, Paper no. IAE-M 02/72. [Available from Centro Tecnológico Aeroespacial, 12200, Sâo José dos Campos, Sâo Paulo, Brazil.] 29 pp.

Wright, P. B., and J. M. Wallace, 1983: Analysis of the marine data set. Trop. Ocean Atmos. Newslett., Nov., 13-14.

Yamazaki, Y., and V. B. Rao, 1977: Tropical cloudiness over the South Atlantic Ocean. J. Meteor. Soc. Japan, 55, 205-207. 